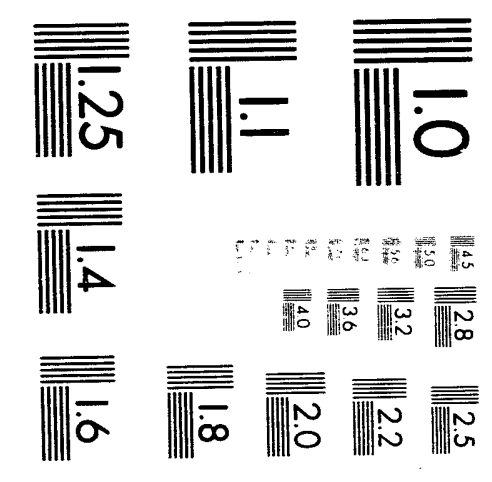



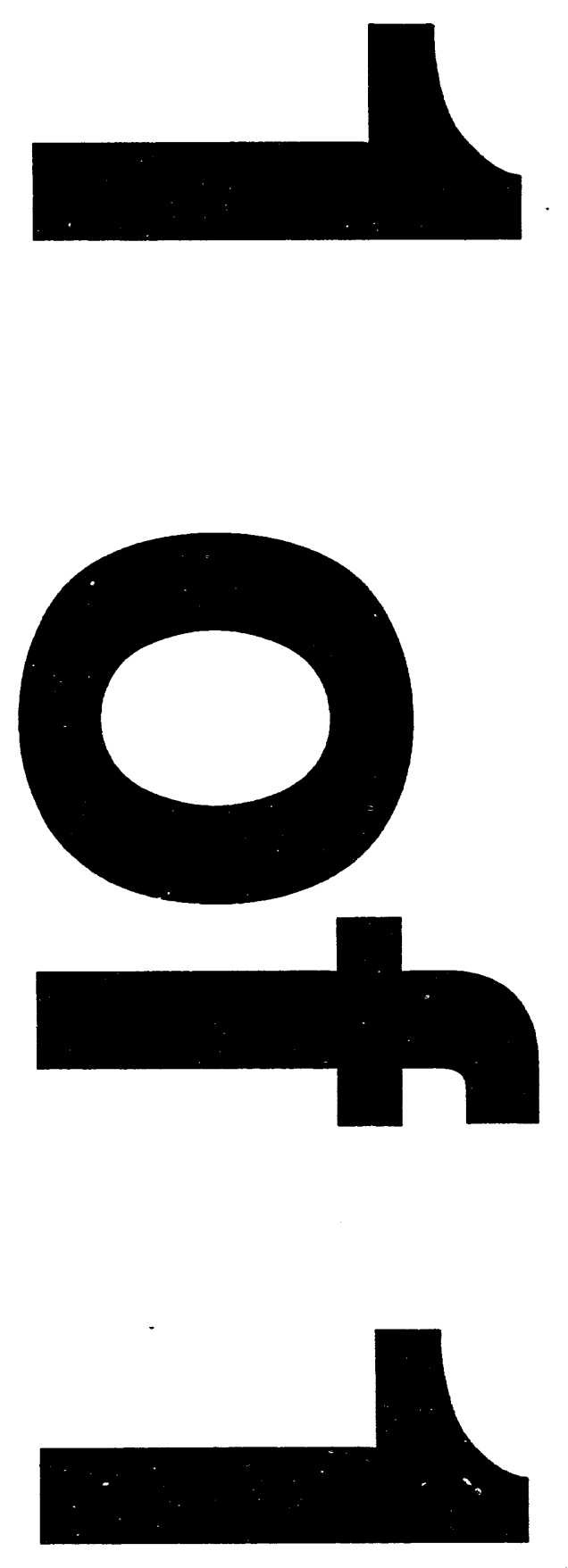
GA-A21448

\title{
EVALUATION OF HELIUM COOLING FOR FUSION DIVERTORS
}

\author{
by \\ C.B. BAXI and THE GA DIVERTOR TEAM
}

This is a preprint of a paper to be presented at the IAEA Technical Committee Meeting on Fusion Studies, September 13-17, 1993, in Los Angeles, California, and to be printed in the Proceedings.

\author{
Work supported by \\ U.S. Department of Energy \\ Contract DE-AC03-89ER51114
}

GENERAL ATOMICS PROJECTS 3466 and 4437

SEPTEMBER 1993

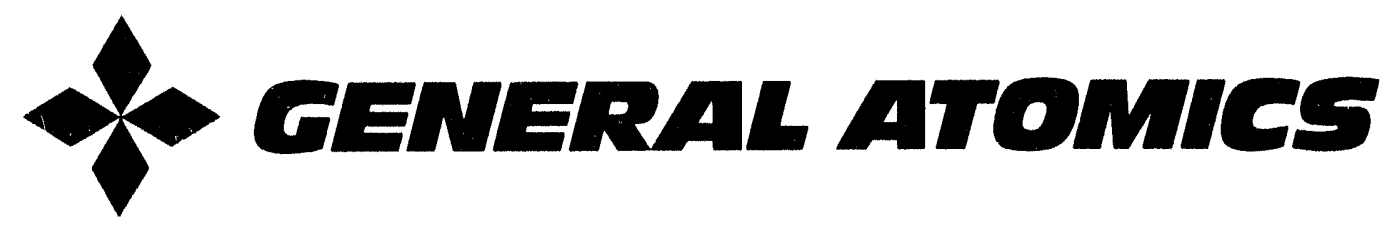




\title{
EVALUATION OF HELIUM COOLING FOR FUSION DIVERTORS
}

\author{
C.B. Baxi and The GA Divertor Team \\ General Atomics, P.O. Box 85608, San Diego, California 92186-9784
}

The divertors of future fusion reactors will have a power throughput of several hundred MW. The peak heat flux on the divertor surface is estimated to be 5 to $15 \mathrm{MW} / \mathrm{m}^{2}$ at an average heat flux of $2 \mathrm{MW} / \mathrm{m}^{2}$. The divertors have a requirement of both minimum temperature $\left(100^{\circ} \mathrm{C}\right)$ and maximum temperature. The minimum temperature is dictated by the requirement to reduce the absorption of plasma, and the maximum temperature is determined by the thermo-mechanical properties of the plasma facing materials.

Coolants that have been considered for fusion reactors are water, liquid metals and helium. Helium cooling has been shown to be very attractive from safety and other considerations. Helium is chemically and neutronically inert and is suitable for power conversion.

The challenges associated with helium cooling are:

1) Manifold sizes

2) Pumping power

3) Leak prevention

In this paper the first two of the above design issues are addressed. A variety of heat transfer enhancement techniques are considered to demonstrate that the manifold sizes and the pumping power can be reduced to acceptable levels.

A helium-cooled divertor module was designed and fabricated by GA for steady-state heat flux of $10 \mathrm{MW} / \mathrm{m}^{2}$. This module was recently (August 1993) tested at Sandia National Laboratories. At an inlet pressure of $4 \mathrm{MPa}$, the module was tested at a steady-state heat flux of $10 \mathrm{MW} / \mathrm{m}^{2}$. The pumping power required was less than $1 \%$ of the power removed. These results verified the design prediction.

\section{INTRODUCTION}

Three coolants considered for the next generation of fusion machines such as the Tokamak Physics Experiment (TPX), the International Thermonuclear Experiment (ITER), and the Next European Tokamak (NET) [1-3] are water, liquid metal and helium gas. From safety considerations helium is the best coolant [4].

In order to evaluate the feasibility of helium cooling, a study was undertaken at GA during 1992-1993 to evaluate if a module could be designed to remove ITER-relevant heat fluxes with helium cooling. This paper describes the design, fabrication and testing results of this module.

The conclusions reached from the GA study were used to analyze the thermal hydraulic performance for the helium-cooled ITER divertor. Two designs were examined. The first was at a moderate helium pressure of $5 \mathrm{MPa}$ but with a highly enhanced heat transfer surface. The second was with a high helium pressure $(20 \mathrm{MPa})$ but with a very moderate heat transfer enhancement. In practice a combination of high pressure and enhancement technique will lead to practical divertor designs for fusion reactors.

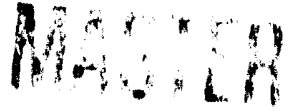




\section{PUMPING POWER AND FLOW}

The pumping power and flow rate are two very important parameters which determine the feasibility of using helium to cool the fusion divertors (and or blankets). An approximate expression [5] for the required pumping power $N$, to remove total power $Q$ is (nomenclature is at the end of the paper):

$$
\frac{Q}{N}=\frac{Q}{\left(M \Delta p / \rho_{1} \eta\right)}
$$

Since

$$
\begin{aligned}
& Q=M C p\left(T_{2}-T_{1}\right)=\alpha(T w-\bar{T}) P L, \\
& \Delta p=\frac{M^{2}}{\bar{\rho} A^{2}}\left(\frac{f L}{2 D h}\right),
\end{aligned}
$$

and

$$
S t=\frac{\alpha A}{M C p}
$$

Equation (1) reduces to:

$$
\frac{Q}{N}=\frac{8 \eta P^{2} L^{2}(T w-\bar{T})^{3}}{Q^{2}} \rho_{1} \bar{\rho} C p^{3} \frac{S t^{3}}{f} .
$$

The volumetric flow rate $\mathrm{V}$, required to remove a peak heat flux of $q^{\prime \prime}$ max, at an inlet temperature of $T_{1}$, and peak wall temperature $T w_{\max }$ is given by:

$$
\mathrm{V}=\frac{\mathrm{Q}}{\rho_{2} C p\left[T w_{\max }-T_{1}-\left(\frac{q_{\text {max }}^{\prime \prime}}{\alpha}\right)\right]} .
$$

Equations ( 2 ) and (3) show that, the pumping power and volumetric flow rate could be reduced by:

1) Increasing the coolant pressure,

2) Increase the heat transfer coefficient,

3) Reducing the length,

4) Reducing the peak heat flux and the power to be removed,

5) Reducing the inlet coolant temperature,

6) Increasing the allowable peak temperature.

A higher coolant pressure results in larger stresses in the cooling tubes. The use of high pressure is also limited by availability of high pressure components such as circulators and 
heat exchangers. The length of the coolant passages are determined by the divertor geometry. Physics design efforts are underway to reduce the power flow and the peak heat flux on the divertor by using techniques such as the radiative divertor. Other than these physics design efforts, heat transfer enhancement techniques offer the best promise to make helium cooling practical for ITER. In practice, the benefit obtained by enhancement techniques is larger than indicated by Eqs (2) and (3), because, the enhancement has to he applied over the length with high heat flux only. This area may be only $10 \%$ in the case of the ITER divertor. Any enhancement technique used to obtain a higher heat transfer coefficient (e.g. roughening the walls) also results in an increase in the friction factor. However, as seen from Eq. (2), the Stanton number (non-dimensional heat transfer coefficient) has an exponent of 3, compared to an exponent of 1 for the friction factor. The net result is to decrease the flow and the pumping power required to attain the same thermal performance.

\section{TEST MODULE DESIGN}

\subsection{Design Basis}

The purpose of this task was to design, fabricate and test a helium-cooled divertor module for ITER-relevant heat flux conditions. The module was tested at the plasma materials testing laboratory of Sandia National Laboratory, Albuquerque (SNLA). The maximum pressure and flow rate for the helium loop at SNLA are $4 \mathrm{MPa}$ and ()$.(25 \mathrm{~kg} / \mathrm{s}$, respectively. The peak heat flux for the ITER divertor is $5 \mathrm{MW} / \mathrm{m}^{2}$. The GA divertor module was designed for twice the ITER heat flux and flow conditions. These heat flux parameters, and the size of the test vacuum chamber limited the heated size of the module to $25 \mathrm{~mm}$ wide and $80 \mathrm{~mm}$ length. The material selected for fabrication of the GA divertor module was dispersion strengthened copper (DSC) with a peak surface limitation of $50\left(0^{\circ} \mathrm{C}\right.$ as determined by creep limits at temperature.

\subsection{Thermal Hydraulic Optimization}

Standard correlation's for the heat transfer coefficient, friction factor and inlet and exit losses from Refs. [6] and [7] were used for the thermal design of the module. The properties of helium were based on Ref. [8]. All calculations were done for an inlet pressure of $4 \mathrm{MPa}$, an inlet coolant temperature of $20^{\circ} \mathrm{C}$, a surface heat flux of $10 \mathrm{MW} / \mathrm{m}^{2}$ and a peak surface temperature of $500^{\circ} \mathrm{C}$.

The simplest design will consist of a smooth channel. The required flow rate is $0.23 \mathrm{~kg} / \mathrm{s}$ and the required flow velocity is $450 \mathrm{~m} / \mathrm{s}$ if smooth channels are used to cool the module. The helium inlet pressure is $4 \mathrm{MPa}$. The corresponding pressure drop will be 0.64 bar, and the pumping power will be $2300 \mathrm{~W}$. Thus the pumping power is $11.5 \%$ of the power removed if a smooth channel is used for cooling. These values are too large. Equation (2) shows that this performance can be improved by increasing the heat transfer coefficient.

A two-dimensional roughness increases both the heat transfer coefficient in the turbulent flow regime by a factor of about 1.8 and the friction factor by a factor of about 4 at a given Reynolds number [6]. Such surfaces have been used successfully in gas cooled reactor programs to reduce the pumping power [9]. With the two-dimensional rough surface, the required heat transfer coefficient can be obtained at a lower velocity of $230 \mathrm{~m} / \mathrm{s}$. The resulting pressure drop is $0.66 \mathrm{bar}$, and the pumping power is $1183 \mathrm{~W}$.

For a 3-D roughness the heat transfer multiplier is about 2.5 and the friction factor multiplicr is about 7 at the same Reynolds number [7]. The required flow velocity is reduced to 141 $\mathrm{m} / 3$, the pressure drop is 0.44 bar and pumping power is $487 \mathrm{~W}$ respectively. Thus the 3-D 
roughness reduces the required pumping power by a factor of 4.7 relative to the smooth channel.

Another possible enhancement technique is the use of impinging jets. The average heat transfer coefficient created by a jet impinging on a flat plate can be obtained by correlations from Ref. [10]. Using a pitch of $1 \mathrm{~mm}$, an arrival jet velocity of about $180 \mathrm{~m} / \mathrm{s}$ will be required to obtain a heat transfer coefficient of $40,000 \mathrm{~W} / \mathrm{m}^{2}{ }^{\circ} \mathrm{C}$. This corresponds to a pressure drop of about 1.1 bar at a flow rate of $0.026 \mathrm{~kg} / \mathrm{s}$. The resulting pumping power is $480 \mathrm{~W}$. This is a vast improvement over flow through a smooth channel but still represents a significant $2.8 \%$ of the power removed. Also manifolding will be complex with jet cooling.

Although cooling by jets results in relatively high pressure drop and pumping power, it has two distinct advantages:

1) The performance does not depend on thermal conductivity of the material as in the case of extended surfaces.

2) It is desirable to make longer modules (the module considered here is only $80 \mathrm{~mm}$ long!). The pressure drop due to jets will not depend on the length of the module. For the ITER divertor, the length with the peak heat flux will be $0.3 \mathrm{~m}$ or longer.

A large increase in the effective heat transfer coefficient can be obtained by using extended surfaces (i.e., fins). Extended surfaces increase the effective heat transfer coefficient by three mechanisms:

1) The reduced flow area increases the flow velocity.

2) The hydraulic diameter is smaller.

3) The heat transfer area is increased.

The overall effect can be (depending on the coolant, fin material, etc.) an increase in the heat transfer coefficient by a factor of 5 to 10 over the smooth channel value, for a given flow and flow channel cross section. All the factors listed above also contribute to an increase in friction factor and pressure drop. However, as seen from Eq. (2), the net effect is to reduce the required flow and pumping power.

The heat transfer coefficient on the surface of the fins was calculated by standard correlations. The effective heat transfer coefficient $\alpha_{e}$ can be calculated from the fin area, fin efficiency, and heat transfer coefficient on the fin surface [5].

Since there are many variables which determine the surface temperature of the module (flow rate, fin pitch, thickness, height, material thermal conductivity), the effect of each variable will be examined. A computer program was developed to perform this study. An optimization study was performed to find the best height, pitch and width which resulted in the minimum pumping power. The details of the optimization are reported in Ref. [5].

Thus the optimized extended surface design consisted of a pitch of $1 \mathrm{~mm}$, a height of $10 \mathrm{~mm}$ and pitch to thickness ratio of 2.5 . For this geometry, the pumping power for a copper module at a heat flux of $10 \mathrm{MW} / \mathrm{m}^{2}$ is $50 \mathrm{~W}$, i.e., $0.25 \%$ of the power removed. This is a factor of 45 improvement over use of a smooth channel!

Further improvement (but very small) can be obtained by offset fins [6]. The principle behind this concept is use of the developing boundary layer in the entrance region to obtain a higher heat transfer coefficient. Analysis shows that the pumping power can be reduced to 
$40 \mathrm{~W}$ for the present design with this offset fin concept. Thus only a slight improvement can be obtained over the non-offset fins with the added complexity to the design.

A calculation was also performed for a module made from beryllium. Due to considerably lower (33\% of copper) thermal conductivity of beryllium, the beryllium module requires four times the pumping power compared to copper. Table I shows summary of analysis in this section.

\section{TABLE I \\ SUMMARY OF ANALYSES FOR THE GA DIVERTOR MODULE}

Thermal analysis of different concepts to achieve a surface temperature of $500^{\circ} \mathrm{C}$. Heat flux $=10$ $\mathrm{MW} / \mathrm{m}^{2}$; wall thickness $=3 \mathrm{~mm}$, helium pressure $=4 \mathrm{MPa}(580 \mathrm{psia})$. The module is $80 \mathrm{~mm}$ long and $25 \mathrm{~mm}$ wide.

\begin{tabular}{|c|l|c|c|c|c|}
\hline Matcrial & \multicolumn{1}{|c|}{ Concept } & $\begin{array}{c}\text { Flow } \\
\text { Required } \\
(\mathrm{kg} / \mathrm{s})\end{array}$ & $\begin{array}{c}\text { Heat Transfer } \\
\text { Coefficient } \\
\left(\mathrm{MW} / \mathrm{m}^{2}-{ }^{\circ} \mathrm{C}\right)\end{array}$ & $\begin{array}{c}\text { Pressure } \\
\text { Drop } \\
(\mathrm{MPa})\end{array}$ & $\begin{array}{c}\text { Pumping } \\
\text { Power } \\
{[\mathrm{M} \text { W }(\%)]}\end{array}$ \\
\hline $\mathrm{Cu}$ & Smooth tubes & 0.230 & 0.026 & 0.064 & $230(11.5 \%)$ \\
$\mathrm{Cu}$ & 2-D rough tube & 0.120 & 0.028 & 0.066 & $1180(5.9 \%)$ \\
$\mathrm{Cu}$ & 3-D rough tubes & 0.072 & 0.029 & 0.044 & $480(2.4 \%)$ \\
$\mathrm{Cu}$ & Jets & 0.026 & 0.040 & 0.1 & $490(2.45)$ \\
$\mathrm{Cu}$ & Optimized fins & 0.026 & 0.040 & 0.012 & $50(0.25 \%)$ \\
$\mathrm{Cu}$ & Offset fins & 0.025 & 0.042 & 0.01 & $40(0.20 \%)$ \\
$\mathrm{Be}$ & Optimized fins & 0.040 & 0.040 & 0.035 & $200(1 \%)$ \\
\hline
\end{tabular}

\subsection{Module Fabrication}

A divertor module with a heated length of $80 \mathrm{~mm}$, fin height of $5 \mathrm{~mm}$, fin pitch of $1 \mathrm{~mm}$ and a fin thickness of $0.4 \mathrm{~mm}$ was fabricated out of DSC material by an electro discharge machining (EDM) process. The fin height of the fabricated module is half the value found in the optimizing study, for ease of fabrication. This will degrade the thermal performance to some extent but will still permit verification of the analysis methods. Figure 1 shows the fabricated module.

\subsection{Test Results}

The tests were conducted (from August 13th through August 18, 1993) at the plasma materials testing laboratory of the Sandia National Laboratory. The heat source was an electron beam. Following are some preliminary results at the highest helium pressure (4 MPa). The pulse length was 60 seconds, which is adequate to achieve steady state. No damage was detected at the end of these tests.

Tests at lower loop pressure increased the pressure drop and pumping power as discussed in Section 2.

The results in the following table confirmed the design predictions. 


\begin{tabular}{|c|c|c|c|}
\hline $\begin{array}{c}\text { Flow Rate } \\
(\mathrm{kg} / \mathrm{s})\end{array}$ & $\begin{array}{c}\text { Heat Flux } \\
\left(\mathrm{MW} / \mathrm{m}^{2}\right)\end{array}$ & $\begin{array}{c}\text { Peak Surface } \\
\text { Temperature } \\
\left({ }^{\circ} \mathrm{C}\right)\end{array}$ & $\begin{array}{c}\text { Pumping Power } \\
\text { [W }(\% \text { of } \\
\text { power removed] }\end{array}$ \\
\hline 0.022 & 10 & 380 & $157(0.8)$ \\
0.011 & 6 & 422 & $21(0.2)$ \\
0.0064 & 3 & 424 & $3.4(0.06)$ \\
\hline
\end{tabular}

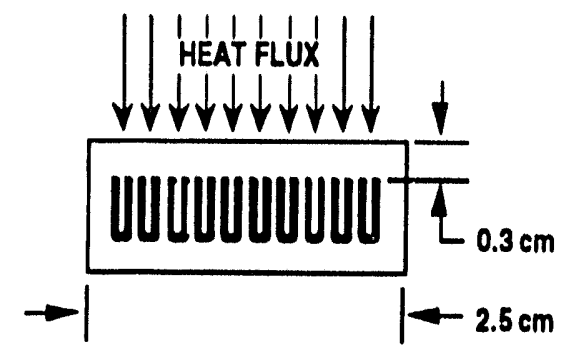

MATERIAL: Dispersion strengthened copper
(GLIDCOP by SCM)
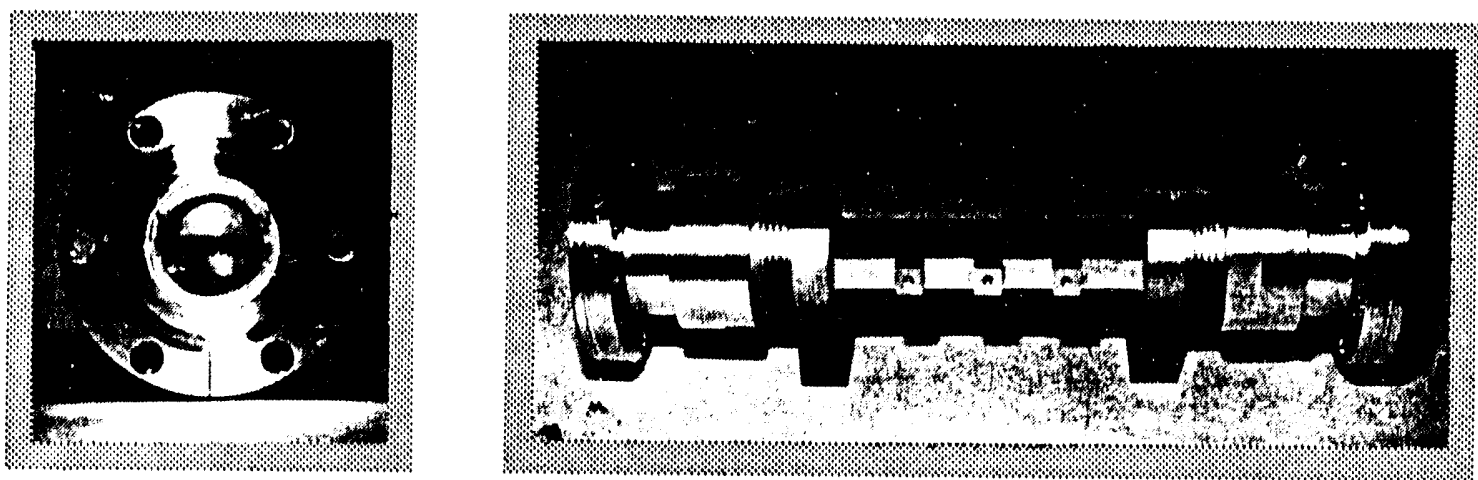

Fig. 1. GA divertor module

\section{ITER DIVERTOR DESIGNS}

Derivations in Section 2 and tests described in Section 3 indicate that an ITER-relevant divertor design with helium cooling is feasible with a combination of heat transfer enhancement techniques and high pressure helium. Two designs are discussed in this section which apply these principles.

\subsection{Design Based on Enhancement}

A configuration of the ITER divertor under consideration (as of May 1993) is shown in Fig. 2. The outside diameter of the tubes is $40 \mathrm{~mm}$ and an average length of the tubes is $3 \mathrm{~m}$. 


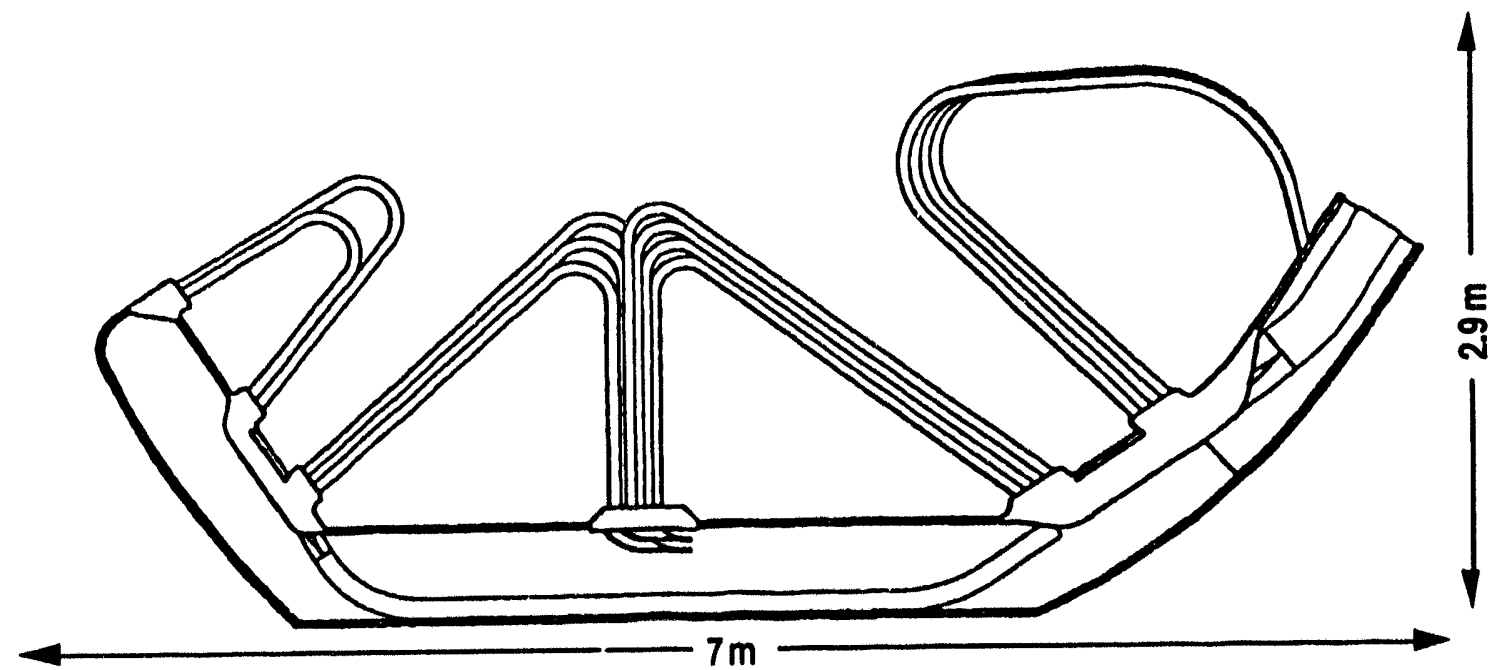

Fig. 2. Conceptual design of the ITER divertor

The cross section of the divertor looks like Fig. 3. Additional data and limits assumed to perform the analysis were:

Beryllium armor thickness $=5 \mathrm{~mm}$

Tube of DSC with $2 \mathrm{~mm}$ wall thickness

Peak heat flux $5 \mathrm{MW} / \mathrm{m}^{2}$ over $10 \%$ of divertor area

Average heat flux $2 \mathrm{MW} / \mathrm{m}^{2}$ on the rest of the surface

Total power to divertor $=480 \mathrm{MW}$

Helium pressure $=5 \mathrm{MPa}$

Inlet He temperature $=150^{\circ} \mathrm{C}$

Peak beryllium temperature $=700^{\circ} \mathrm{C}$

A computer program was written to study the effect of the different techniques used in designing the module to cool the ITER divertor shown in Fig. 3. Helium pressure of $5 \mathrm{MPa}$

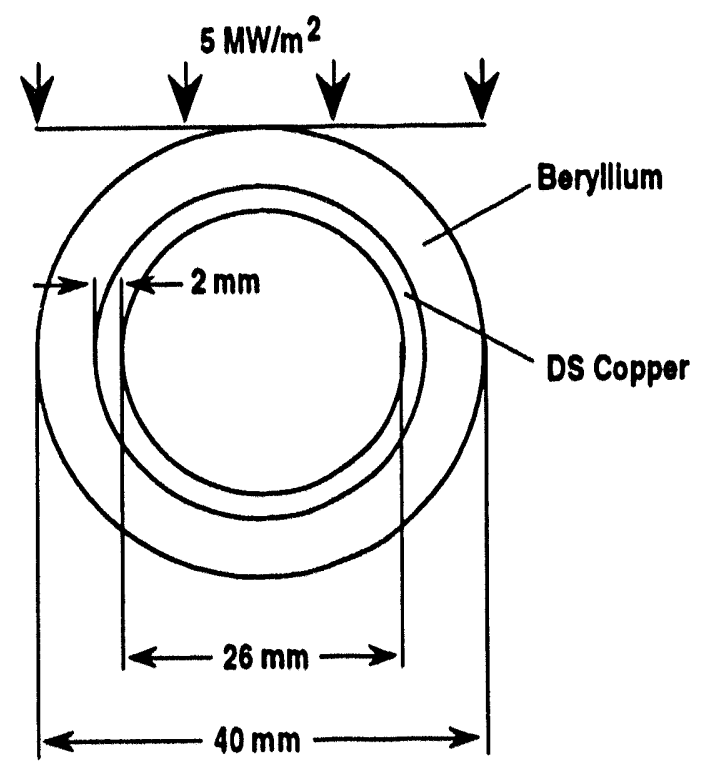

Fig. 3. Cross section of the flow channel in ITER divertor 
was chosen for this study as this is the pressure in current designs [9] of the high temperature gas cooled reactor (HTGR). All the out of vessel components required at this pressure of helium are already available.

The simplest design will consist of smooth tubes. The following flow parameters are obtained for a smooth tube design:

Flow required $=2800 \mathrm{~kg} / \mathrm{s}$

Pumping power $=615 \mathrm{MW}$

Both these values are too large. The pumping power is $128 \%$ of the power removed. In order to handle the flow of $2800 \mathrm{~kg} / \mathrm{s}$, very large manifolds (12 inlet and exit manifolds of about $0.50 \mathrm{~m}$ diameter each) will be required.

Table II shows how the flow rate and pumping power can be reduced by use of heat transfer enhancement techniques. In all these cases the enhancement was applied over $10 \%$ of the length based on the assumption that the peak heat flux is over $10 \%$ of the divertor length. The computer program is one dimensional and the cross section of the divertor is two dimensional (due to azimuthal variation of the heat flux). Hence a two-dimensional finite element analysis of each of the geometries was performed and suitable correction factors applied to the thermal hydraulic calculations.

\section{TABLE ॥}

\section{SUMMARY OF ANALYSIS FOR THE 5 MPa DESIGN}

\section{DATA}

Pressure $=5 \mathrm{MPa}, q_{\max }^{\prime \prime}=5 \mathrm{MW} / \mathrm{m}^{2}, q_{a \nu}^{\prime \prime}=2 \mathrm{MW} / \mathrm{m}^{2}$, total $Q=480 \mathrm{MW}, T_{\text {in }}=150^{\circ} \mathrm{C}$, $T_{\max }$ for $\mathrm{Bc}=7(1)^{\circ} \mathrm{C}, \mathrm{Be}$ thickness $=5 \mathrm{~mm}, \mathrm{Cu}$ thickness $=2 \mathrm{~mm}$, length $=3 \mathrm{~m}$

\section{RESULTS}

\begin{tabular}{|l|c|c|c|c|c|}
\hline \multicolumn{1}{|c|}{ Geometry } & $\begin{array}{c}\text { Flow } \\
(\mathrm{kg} / \mathrm{s})\end{array}$ & $\begin{array}{c}\text { Peynolds } \\
\text { Number }\end{array}$ & $\begin{array}{c}\text { Velocity } \\
(\mathrm{m} / \mathrm{s})\end{array}$ & $\begin{array}{c}\text { Pressure } \\
\text { Prop } \\
(\mathrm{MPa})\end{array}$ & $\begin{array}{c}\text { Pumping } \\
\text { Power } \\
{[\mathrm{MW}(\%)]}\end{array}$ \\
\hline Smooth & 2800 & $2.8 \times 10^{6}$ & 510 & 1.1 & $615(128)$ \\
2-D rough & 1500 & $1.6 \times 10^{6}$ & 270 & 0.47 & $130(27)$ \\
Twisted tape & 1250 & $1.3 \times 10^{6}$ & 230 & 0.3 & $71(15)$ \\
3-D rough & 920 & $9.7 \times 10^{5}$ & 170 & 0.24 & $42(9)$ \\
Extended surface & 430 & $4.6 \times 10^{5}$ & 84 & 0.21 & $20(4.1)$ \\
\hline
\end{tabular}

Two types of extended surfaces were considered. The finite element analysis, performed on the finite element code COSMOS [11], is shown in Figs. 4 and 5 for straight and radial fins. The geometry with the radial fins could be fabricated by excrusion (although not with DSC).

Thus, a helium cooled design at a pressure of $5 \mathrm{MPa}$ with a pumping power less than $5 \%$ is possible. Using an extended surface may result in increases in hardware costs and this needs further study. 


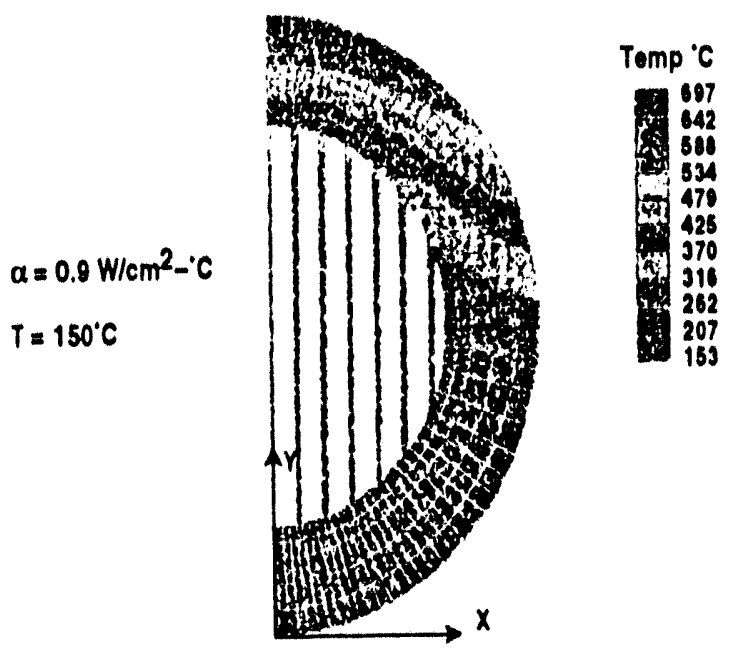

Fig. 4. Finite element analysis of the straight fin concept for the ITER divertor

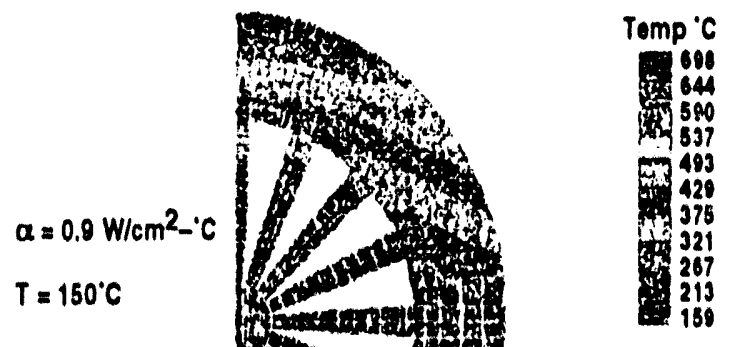

Fig. 5. Finite element analysis of the radial fin concept for the ITER divertor

\subsubsection{Manifold Sizes}

For the design with extended surfaces, the now required is $4.30 \mathrm{~kg} / \mathrm{s}$. The manifold sizes inside the machine will be:

Number: 12 inlet and 12 outlet

Inlet diameter $15 \mathrm{~cm}$

Outlet diameter $17 \mathrm{~cm}$

\subsubsection{Stress Analysis}

A finite element stress analysis (Fig. 6) of the designs indicated that the thermal stress in the copper tube was helow a level of $4(X) \mathrm{MPa}$ at $4(1) 0^{\circ} \mathrm{C}$. However, stresses in the beryllium armor exceed the aceptable levels by a factor of 4 . New joining techniques are under development to overcome this problem.

\subsection{High Pressure Design}

A high pressure design of the ITER divertor proposed by P.H. Rebut, is shown in Fig. 7. The two important features of this design are: 1) no brazes and 2 ) helium at a pressure of 20 MPa. This design needs a very high helium pressure to be viable due to small diameter of the flow channels. Also, the coolant tubes are spirally wound along the length. This is required to insure that all coolant tubes participate in heat removal.

Thermal hydraulic analysis of this design was performed with the following parameters:

Inlet helium pressure $=20 \mathrm{MPa}$

Coolant temperature at high heat flux location $20\left(0^{\circ} \mathrm{C}\right.$

If the cooling tubes are smooth, even at very high helium pressure, the flow required is very large $(840 \mathrm{~kg} / \mathrm{s})$ due to:

1) Small tube diameter

2) Thermal resistance of liquid metal inter phase

3) Distance hetween half the tubes and the heat flux surface. 


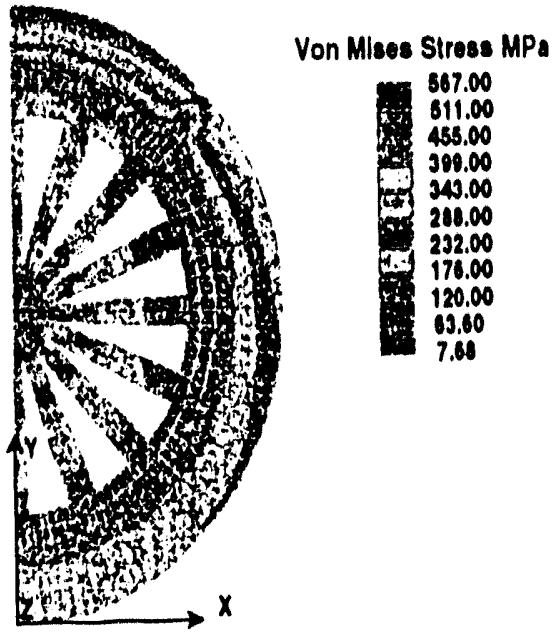

Fig. 6. Stress analysis for a adial fin geometry

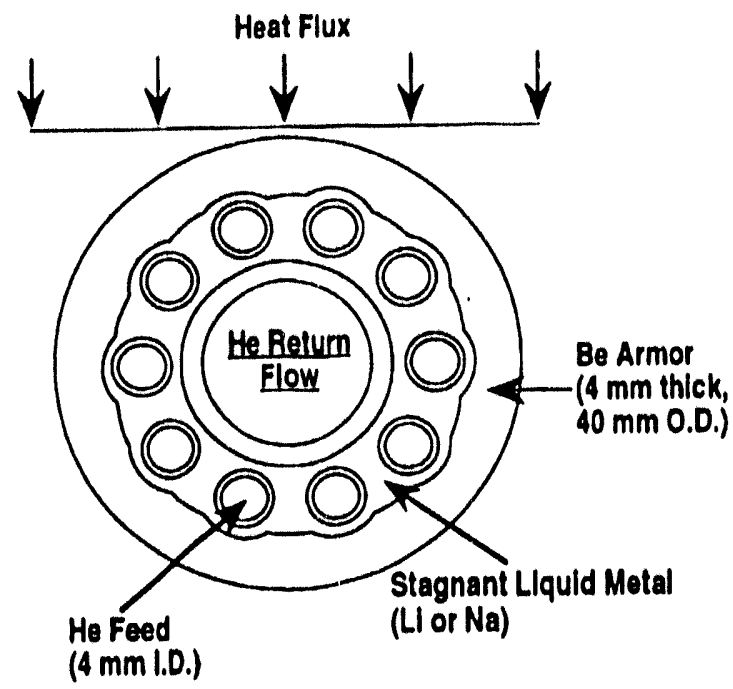

Fig. 7. A high pressure hellum-cooled design for ITER

The performance can be improved by using a heat transfer enhancement such as roughness or spiral ribs inside the cooling tubes. This will increase the heat transfer coeflicient by about a factor of 2 and the friction by a factor of 4 . As before, it will be assumed that the enhancement is applied over $10 \%$ of the length.

The finite element analysis of this design is shown in Fig. 8. The heat transfer in the coolant channels was increased to obtain a surface temperature close to $7000^{\circ} \mathrm{C}$. The equivalent heat transfer coefficient required to obtain this temperature was $0.05 \mathrm{MW} / \mathrm{m}^{2}{ }^{\circ} \mathrm{C}$. To remove the $480 \mathrm{MW}$ of power with $5 \mathrm{MW} / \mathrm{m}^{2}$ peak heat flux with this design the following parameters are required:

\begin{tabular}{|l|c|c|c|c|}
\hline Geometry & $\begin{array}{c}\text { Flow } \\
(\mathrm{kg} / \mathrm{s})\end{array}$ & $\begin{array}{c}\text { Flow } \\
\text { Velocity } \\
(\mathrm{m} / \mathrm{s})\end{array}$ & $\begin{array}{c}\text { Pressure } \\
\text { Drop } \\
(\mathrm{MPa})\end{array}$ & $\begin{array}{c}\text { Pumping } \\
\text { Power } \\
{[\mathrm{MW}(\%)]}\end{array}$ \\
\hline Smooth & 840 & 190 & 3.0 & $130(27 \%)$ \\
Helical ribs & 400 & 90 & 1.3 & $23(5 \%)$ \\
\hline
\end{tabular}

Analysis was also performed for vanadium tubes. Due to the lower thermal conductivity of vanadium, the peak temperature was about $150^{\circ} \mathrm{C}$ higher.

The thermal stress analysis of the above design showed that, the stresses in cooling tubes were below the limits. However, the thermal stress in the beryllium armor was about 380 $\mathrm{MPa}$, which is 2.3 times the allowable stress.

The flow rate and pumping power required for this design are similar to low pressure design presented in the last section and summarized in Table II. The manifold diameter will be half due to high pressure. 


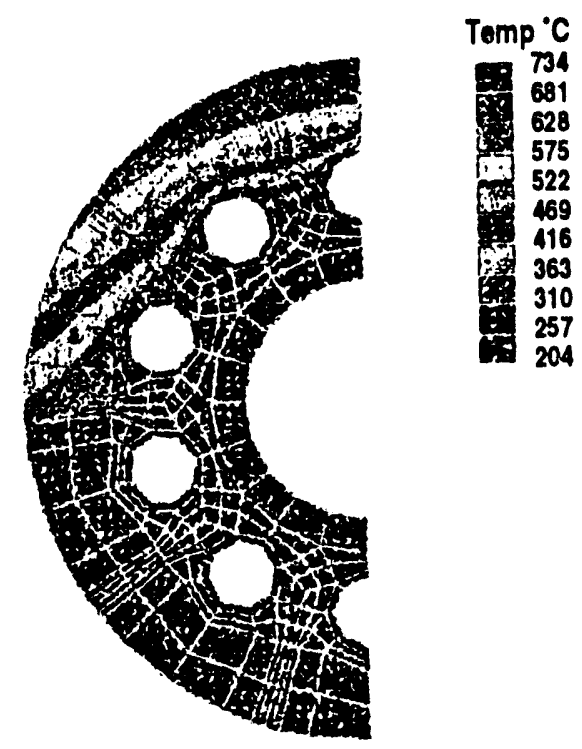

Fig. 8. Finite element analysis of the high pressure design

\section{CONCLUSIONS}

As a result of this evaluation, the following conclusions were reached:

1) Helium cooling of fusion divertors can be achieved at pressures of about $5 \mathrm{MPa}$.

2) A heiium cooled divertor design for steady state fusion machines is feasible, with a pumping power less than $5 \%$ of the power removed.

3) The flow rate and the pumping power required can be minimized by a combination of enhancement techniques and high pressure.

4) A trade-off study to compare the hardware costs of enhancement techniques and high pressure is required.

5) Power conversion system components for helium cooling of fusion divertors are available now.

6) Experimental results confirm the analysis methods in this paper and demonstrate that helium cooling of fusion divertors is practical.

\section{ACKNOWLEDGMENTS}

The author wishes to thank D.L. Sevier, J.P. Smith, P. Trester, and M. DiMartino for fabrication of the test module, $K$. Redler for help with finite element calculations and D. Yochison for conducting the experiments at SNLA. The funding for the design and fabrication of the module was provided by General Atomics. The ITER divertor analysis task was supported by the U.S. Department of Energy under Contract No. DE-AC03-89ER51114.

\section{REFERENCES}

[1] ITER Concept Definition, ITER Documentation Series No. 3, IAEA, Vienna, 1989.

[2] Haines, J., "BPX Divertor Design and R\&D Program," 14th Symposium on Fusion Engineering, San Diego, California. 
[3] Schlosser, J., et al., "Development of High Heat Flux Components for Continuous Operation in Tokamaks," 14th Symposium on Fusion Engineering, San Diego, California.

[4] Piet, S.J., and D.A. Petti, "U.S. Position Paper for Safety and Environment Activities Related to ITER," ITER/US/93/TE/SE-2, February, 1993.

[5] Baxi, C.B., "Design and Analysis of Helium-Cooled Divertor Module for Fusion Reactors," presented at SPIE 1993, to be published in the transactions, July 1993.

[6] "Handbook of Single-Phase Convective Heat Transfer," Edited by S. Kayak, Wiley, 1987.

[7] "Handbook of Heat Transfer," W. Rohsenow, editor, McGraw-Hill, New York, 1985.

[8] Goodman, J., et al., "Thermodynamic and Transport Properties of Helium," General Atomics Report GA-A134500, October 1975.

[9] Melese, G., and R. Katz, Editors, "Thermal and Flow Design of Helium-Cooled Reactors," American Nuclear Society Publication, 1984.

[10] Gordon, R., and J. Cobonque, "Heat Transfer Between a Flat Plate and Jets of Air Impinging On It," International Developments in Heat Transfer, pp. 454

[11] "COSMOS, A Finite Element Analysis Code," Structural Research, Santa Monica, California code

\section{NOMENCLATURE}

$$
\begin{array}{ll}
A & =\text { flow area } \\
C p & =\text { specific heat of coolant } \\
D_{h} & =\text { hydraulic diameter } \\
f & =\text { friction factor } \\
\alpha & =\text { heat transfer coefficient } \\
L & =\text { length of the flow passage } \\
M & =\text { mass flow rate of helium } \\
N & =\text { pumping power } \\
\Delta p & =\text { pressure drop } \\
P & =\text { perimeter } \\
P r & =\text { Prandtl number } \\
Q & =\text { total power removed } \\
q^{\circ \prime} & =\text { heat flux }
\end{array}
$$

$$
\begin{array}{ll}
S t & =\text { Stanton number } \\
T w & =\text { Wall temperature } \\
T & =\text { coolant temperatures } \\
\bar{T} & =\text { average coolant temperature } \\
\mathrm{V} & =\text { volumetric flow rate of helium } \\
\eta & =\text { circulator efficiency } \\
\rho & =\text { density of helium } \\
\bar{\rho} & =\text { average density of helium }
\end{array}
$$

Subscripts:

$$
\begin{aligned}
& 1=\text { inlet } \\
& 2=\text { outlet } \\
& \max =\text { maximum }
\end{aligned}
$$



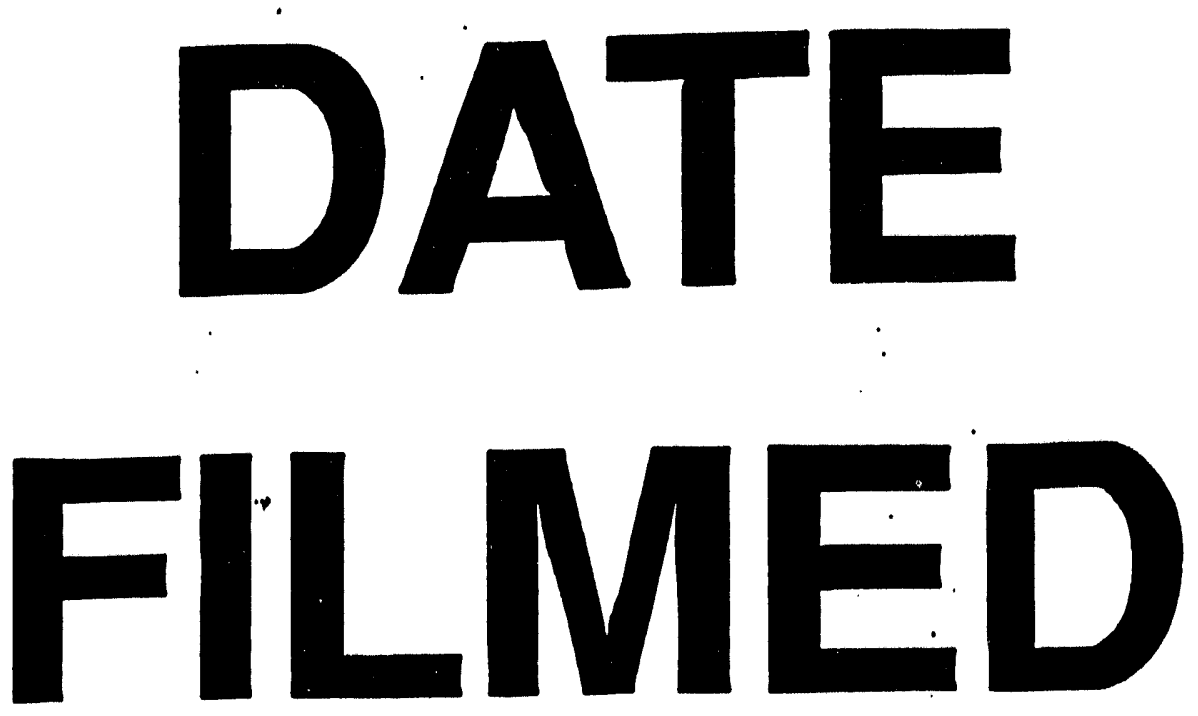

$1 / 11 / 94$
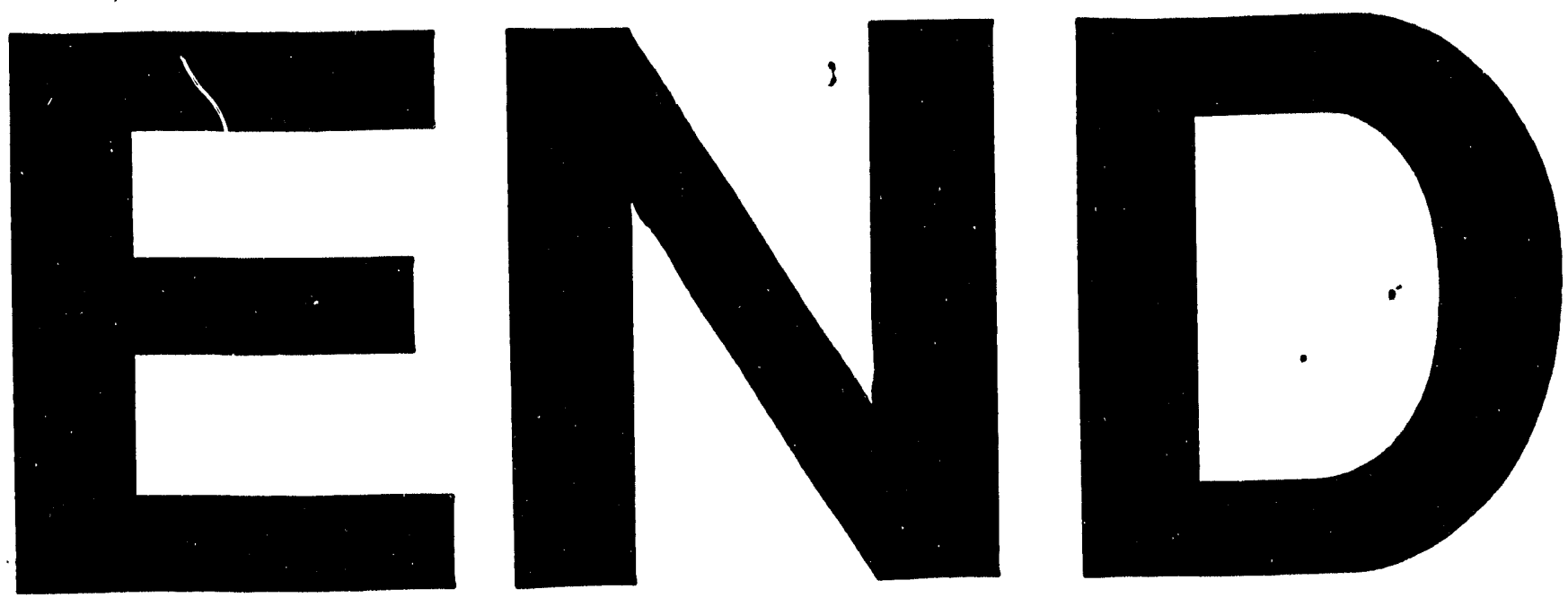


$$
-
$$

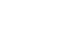

